\title{
O GÊNERO PSEUDOGNAPHALIUM KIRP. (ASTERACEAE-GNAPHALIEAE) NO SUL DO BRASIL ${ }^{1}$
}

\author{
LEONARDO PAZ DEBLE² JOSÉ NEWTON CARDOSO MARCHIORI ${ }^{3}$
}

\begin{abstract}
RESUMO
Com distribuição predominantemente neotropical, o gênero Pseudognaphalium Kirp. é separado de Gnaphalium s. str., pela maioria dos autores, por incluir ervas anuais, bianuais ou perenes, com capítulos oblongos até largamente campanulados, pelas brácteas involucrais monocromáticas, pelo estereoma dividido (exceto $P$. oligandrum (DC.) Hilliard \& Burtt), pelas flores femininas em maior número do que as hermafroditas, dispostas em duas ou mais séries, e pelos aquênios ovados até oblongos, de paredes normalmente papilosas, com pêlos esparsos clavados, do tipo "twin-hairs". Muito próximo de Achyrocline (Less.) DC., Pseudognaphalium separa-se pelo maior número de flores nos capítulos. Das quatro espécies reconhecidas para a flora sul-brasileira, Pseudognaphalium austrobrasilicum Deble \& Marchiori constitui novidade para a ciência. São fornecidas diagnoses, ilustrações, distribuição geográfica, sinonímias e uma chave para a distinção das espécies sul-brasileiras do gênero.

Palavras-chave: Pseudognaphalium, flora do sul do Brasil, Gnaphalieae, Asteraceae.
\end{abstract}

\section{ABSTRACT}

Basically neotropical, the genus Pseudognaphalium Kirp. is distinguished from Gnaphalium s. str., by several authors, because it includes annual, biannual or perennial herbs, with oblong or large campanulate heads, monochromous involucral bracts and divided stereome (except to $P$. oligandrum (DC.) Hilliard \& Burtt), as well as for having female florets more numerous than disc-florets, disposed in two or more series, beyond ovate to oblong achenes, sparsely hairy with short, clavate, myxogenic twin-hairs. Closely related to Achyrocline (Less.) DC., Pseudognaphalium differs for having more flowers in each head. Four species of Pseudognaphalium are presently known, one of which, Pseudognaphalium austrobrasilicum Deble \& Marchiori, is here described. Descriptions, illustrations, the geographic distributions, the synonymity and a key for all taxa, are also furnished.

Key words: Pseudognaphalium, southern brazilian flora, Gnaphalieae, Asteraceae.

\section{INTRODUÇÃO}

$\mathrm{O}$ gênero Pseudognaphalium Kirp. abriga cerca de 95 espécies de ervas anuais, bianuais ou perenes, com capítulos oblongos até largamente campanulados, brácteas involucrais com estereoma dividido e aquênios ovados a oblongos, de paredes normalmente papilosas, com pêlos do tipo "twin-hairs". Estreitamente relacionado a Achyrocline (Less.) DC., Pseudognaphalium difere por apresentar flores femininas em duas ou mais séries.
Uma das primeiras contribuições para o conhecimento das espécies sul-americanas de Pseudognaphalium, deve-se ao naturalista francês Jean Baptiste Lamarck (1786), que publicou Gnaphalium cheiranthifolium (atual Pseudognaphalium cheiranthifolium), com base em coleções feitas pelo médico e naturalista francês Philibert Commerson, participante da expedição de Bougainville (1766-1769).

No segundo, dos três volumes do "Prodromus", correspondentes à família Compositae,

\footnotetext{
1 Artigo recebido em 04/01/2006 e aceito para publicação em 31/01/2006.

2 Biólogo, MSc., bolsista CAPES, doutorando do Programa de Pós-Graduação em Engenharia Florestal, Centro de Ciências Rurais, Universidade Federal de Santa Maria. CEP 97105-900, Santa Maria (RS). deble.biol@bol.com.br

3 Engenheiro Florestal, Dr., bolsista de Produtividade em Pesquisa do CNPq, Professor Titular do Departamento de Ciências Florestais, Universidade Federal de Santa Maria. CEP 97105-900, Santa Maria (RS). balduinia@mail.ufsm.br
} 
De Candolle (1837) tratou das espécies de Gnaphalium em sentido amplo. Para a flora sul-brasileira, ele descreveu Gnaphalium gaudichaudianum (hoje Pseudognaphalium gaudichaudianum), com base nas coleções de Charles Gaudichaud-Beaupré, feitas no Rio Grande do Sul, propondo, no mesmo trabalho, a variedade subrufescens, separada da variedade típica pela cor das brácteas involucrais.

$\mathrm{Na}$ "Flora Brasiliensis", Baker (1882) reduziu Gnaphalium gaudichaudianum DC. e G. gaudichaudianum var. subrufescens DC. ao status de variedades de Gnaphalium cheiranthifolium Lamarck.

$\mathrm{O}$ gênero Pseudognaphalium foi criado pelo botânico russo Moisey Elevich Kirpichnikov (1950) para abrigar uma espécie mexicana, descrita por De Candolle (1937) como Gnaphalium oxyphyllum.

O prolífico sinanterólogo Angel Lulio Cabrera elucidou a identidade das espécies sulamericanas de Pseudognaphalium (incluídas em Gnaphalium), em diversas publicações. Em 1961, Cabrera descreveu Gnaphalium leucopeplum (atual Pseudognaphalium leucopeplum), espécie da Argentina, Uruguai e Rio Grande do Sul. O autor reconheceu o novo táxon como próximo a Gnaphalium pellitum Kunth (espécie reduzida, em 1991, à sinonímia de Achyrocline alata, por Dillon \& Sagástegui), a Gnaphalium philippi Cabrera (atual Gnaphalium cabrerae S. E. Freire) e a Gnaphalium cheiranthifolium Lamarck. Para a "Flora Patagonica", Cabrera (1971) apresentou uma chave, diagnoses e ilustrações das oito espécies de Gnaphalium ocorrentes na região, seis das quais são atualmente incluídas em Pseudognaphalium, e duas (Pseudognaphalium gaudichaudianum, Pseudognaphalium leucopeplum) participam, igualmente, da flora sul-brasileira. Em outra contribuição, Cabrera (1974) reconheceu duas espécies para a província de Entre Rios (Argentina) - Gnaphalium cheiranthifolium e Gnaphalium gaudichaudianum. Para a "Flora de la Provincia de Jujuy", Cabrera (1978) con- siderou treze espécies, duas das quais sendo novas para a ciência (Gnaphalium jujuyense e Gnaphalium yalaense). Todas essas espécies foram posteriormente transferidas ao gênero Pseudognaphalium, por Anderberg (1991).

Em 1981, Hilliard \& Burtt inseriram outras onze espécies em Pseudognaphalium, reconhecendo a importância do estereoma dividido para distinção genérica, dentro da tribo Gnaphalieae. No mesmo trabalho, os autores propuseram a divisão do gênero em dois subgêneros: Pseudognaphalium e Laphangium Hilliard \& Burtt.

$\mathrm{Na}$ "Flora Montevidensis", Atilio Lombardo (1983) tratou das espécies de Pseudognaphalium no gênero Gnaphalium, reconhecendo apenas dois táxones para o Uruguai: Gnaphalium gaudichaudianum e G. cheiranthifolium. Em seu estudo, o autor apresentou chave, diagnoses e ilustrações dos mesmos.

Arne Anderberg (1991), autor de importante estudo sobre a taxonomia e filogenia da tribo Gnaphalieae, propôs a transferência de 76 espécies para Pseudognaphalium, considerando o gênero como próximo a Achyrocline (Less.) DC., Chiliocephalum Benth., Helichrysum Mill. e Homognaphalium Kirp., táxones por ele colocados, informalmente, no grupo "Helichrysum".

Para Dillon \& Sagástegui (1991), o gênero Pseudognaphalium não deveria ser aceito, senão após estudo aprofundado sobre os limites genéricos de Achyrocline, Gnaphalium e Stenocline. Desta maneira, os autores trataram as espécies sul-americanas de Pseudognaphalium como subordinadas a Gnaphalium. Para a "Flora do Peru" (1991), os mesmos autores apresentaram chave e diagnoses das sete espécies de Gnaphalium ocorrentes no país, seis das quais figuram, atualmente, no gênero Pseudognaphalium.

Para a "Flora Fanerogámica da Argentina", Freire (1995) considerou Gnaphalium em sentido amplo. A autora apresentou chave, descrições e referências iconográficas das vinte espécies ocorrentes no país, dezessete das quais 
foram incluídas, anteriormente, em Pseudognaphalium, por Anderberg (1991).

Nesom (2001), acrescentou uma nova espécie ao gênero: Pseudognaphalium austrotexanum, do México e Estados Unidos. Mais recentemenete, o autor (2004) apresentou novidades para o complexo de Pseudognaphalium canescens (DC.) A. Anderb., elevando a nível específico três subespécies da mesma. De igual modo, Ballard \& Feller (2004) propuseram status específico para Pseudognaphalium obtusifolium var. saxicola (Fasset) Kartesz, propondo o binômio Pseudognaphalium saxicola (Fasset) Ballard \& Feller.

$\mathrm{Na}$ realização do presente trabalho, foram consultados os seguintes herbários: CESJ, $\mathrm{CNPO}^{4}, \mathrm{HBR}, \mathrm{HAS}, \mathrm{HDCF}^{5}$, ICN, LP, MBM, MCPUC, MVFA, MVJB, MVM, PACA, PEL, SI, SMDB, UPCB, ${ }^{* 6}$ (Siglas de acordo com o "Index Herbariorum").

\section{TRATAMENTO TAXONÔMICO}

\section{Pseudognaphalium Kirp.}

M. E. Kirpichnikov, Acta Inst. Bot. Acad. Sci. S.S.S.R, Ser. 1, n. 9, p. 33, 1950.

TIPO - Pseudognaphalium [Gnaphalium] oxyphyllum DC.

= Hypelychrysum Kirp., Trudy Bot. Inst. Akad. Nauk. S.S.S.R, Ser. 1, Fl. Sist. Vyssh. Rast. 9, p. 33, 1950. [TIPO - Pseudognaphalium [Gnaphalium] heterotrichum Phil.]

Compreende ervas anuais, bianuais ou perenes, de caules simples ou ramosos, normalmente eretos ou ascendentes. As folhas, alternas, sésseis, lineares até ovadas, discolores ou concolores e glabras ou pilosas, possuem margens íntegras ou erosas, por vezes revolutas. Quando presentes, os pêlos podem ser lanosos ou glandulares, não raro entremesclados. A capitulescência, em corimbos ou panículas, é geralmente terminal. Os capítulos, numerosos, podem ter cor marfim, estramínea, amarela, dourada ou ferrugínea. O invólucro, oblongo até largamente campanulado, apresenta brácteas involucrais monocromáticas, dispostas em 4-10séries, com estereoma dividido e receptáculo plano. As flores, amarelas, branco-amareladas, branco-esverdeadas ou rosadas, apresentam dentes ou lóbulos eretos, normalmente providos de pêlos glandulares. As marginais, femininas e em duas ou mais séries, apresentam corola filiforme de tubo engrossado ou não na base, e ápice 3-4dentado. O estigma, exserto ou não ao tubo da corola, apresenta ramos truncados e papilosos no ápice. As flores centrais, hermafroditas, de corola tubulosa e ápice 5-dentado ou 5-lobado, ocorrem em menor número do que as femininas, apresentando anteras caudadas e estigma semelhante ao das flores femininas. Os aquênios, ovados até oblongos, são levemente comprimidos e normalmente papilosos, tendo pêlos esparsos, clavados, do tipo "twin-hairs". O pápus, isomorfo e com cerdas livres entre si, algo aderidas na base pela presença de células patentes, tem, geralmente, o mesmo comprimento da corola. Número cromossômico: $2 \mathrm{n}=14$ (Turner, 1970; Groves 1977).

Das 95 espécies do gênero, cerca de 45 são exclusivas das Américas Central e do Norte; na América do Sul ocorrem cerca de 35 espécies, havendo poucas endêmicas na Ásia (4), África (2) e Europa (3). No Brasil, o gênero está fracamente representado, ocorrendo apenas quatro ou cinco entidades taxonômicas, principalmente na região sul.

\footnotetext{
CNPO, Herbário da Embrapa Pecuária Sul, Bagé (RS).

HDCF, Herbário do Departamento de Ciências Florestais, Santa Maria (RS).

*, Herbário particular do primeiro autor.
} 
CHAVE PARA AS ESPÉCIES

1a. Folhas lanosas em ambas as faces; pêlos glandulares, quando presentes, longos e entremesclados a pêlos lanosos. Brácteas involucrais 6-7-seriadas, agudas ou levemente obtusas no ápice.

2a. Folhas com longos pêlos glandulares entremesclados a pêlos lanosos. Capítulos de coloração amarelo-citrina ou dourada, de 4-5 $\mathrm{mm}$ de altura

2. Pseudognaphalium cheiranthifolium (Lam.) Hilliard \& Burtt.

2b. Folhas desprovidas de pêlos glandulares. Capítulos de coloração estramínea ou amarelada, de 5-6,5 mm de altura. 4. Pseudognaphalium leucopeplum (Cabrera) A. Anderb.

1b. Folhas glandulares na face adaxial, lanosas na abaxial. Brácteas involucrais 8-10-seriadas, obtusas até rotundas no ápice.

3a. Folhas discolores, densamente incano-lanosas na face abaxial. Capítulos de coloração estramínea, com 3-4 $\mathrm{mm}$ de altura por 3-5 mm de diâmetro. Flores femininas, 160-270. Aquênios ovado-oblongos, de 0,4-0,5 $\mathrm{mm}$. 3. Pseudognaphalium gaudichaudianum (DC.) A. Anderb.

3b. Folhas suavemente discolores, lanosas a lanuginosas na face abaxial. Capítulos de coloração marfim, de 4,5-6 $\mathrm{mm}$ de altura por 5-7 mm de diâmetro. Flores femininas, 350-400. Aquênios oblongos, de 0,7 mm.

1. Pseudognaphalium austrobrasilicum Deble \& Marchiori, sp. nov.

\section{Pseudognaphalium austrobrasilicum Deble \& Marchiori, sp. nov.}

TIPO - BRASIL, Rio Grande do Sul, São Sepé, BR 392, p. Santa Maria, após o viaduto da BR 290, em campo, na beira da estrada, abundante, erva glandulosa, ereta, de 90 $\mathrm{cm}$, capítulos brancos, odor fétido intenso, L. P. Deble \& A. S. de Oliveira 5.000, 02.X.2004. Holotypus SI. Isotypi CTES, ICN, MBM, PACA, *.

Herba annua, 50-110 cm alta; caulibus erectis, simplicibus vel apice ramosis, dense glandulosis, usque ad inflorescentiam foliosis. Folia alterna (internodiis 2-15 mm longis), sessilia, linear-lanceolata ad oblanceolata, integra, leviter discolora, supra glanduloso-pubescentia, subtus lanosa vel lanuginosa, 3-13 cm longa, 0,3-1,5 cm lata, apice acuta, base decurrentia (decurrentia usque 3 $\mathrm{cm}$ longa). Capitula multa, cymoso-paniculata glomerata disposita. Involucrum campanulatum, album, 4,5-6 mm altum, 5-7 mm crassum. Bracteis involucralibus 9-10seriatis; externis obovatis, rotundatis, 2-2,5 mm longis, 2 $\mathrm{mm}$ latis, stereomate $0,5 \mathrm{~mm}$ alto; mediis et interioribus spathulatis, 4-5,5 mm longis, 1,7-2 $\mathrm{mm}$ latis, obtusis ad rotundatis, stereomate 1-2,5 mm alto, omnibus dorso cum pilis lanosis et glandulosis. Flores dimorphi: marginales circa 350-400, feminei, corolla filiforme, 3-3, $2 \mathrm{~mm}$ longa, apice 3-dentata, dentibus deltoides, brevissimis, cum pilis glandulosis; stylo 3,5 mm longo, rami cum 0,5-0,7 mm, apice truncati, papilosi; flores disci, 30-35, hermaphroditi, corolla tubulosa, 2,5-2,8 mm longa, 5-dentata, dentibus deltoides, circa 0,5 mm longis, cum pilis glandulosis; antherae 1,6-1,8 mm longae, caudatae; caudae elongatae, barbatae, apice oblongo trigonae, subacutae. Achaenia papilosa, castanea, oblonga, 0,7 mm longa. Pappus albus, setae 3,5 mm longae; cellulis apicalibus obtusis, basi patentibus.
Erva anual, ereta, densamente glandulosa, de caules eretos, simples ou ramosos no ápice e $50-110 \mathrm{~cm}$ de altura (Figura 1a). Folhas alternas (entre-nós de 2-15 mm), sésseis, linearlanceoladas a oblanceoladas $(3-13 \mathrm{~cm}$ de comprimento por $0,3-1,5 \mathrm{~cm}$ de largura), de margens íntegras ou erosas, levemente discolores, lanosas ou lanuginosas na face abaxial, densamente coberta de pêlos glandulares na adaxial, com ápice agudo e base decurrente (decurrência de até $3 \mathrm{~cm}$ ) (Figura 1a). Capítulos numerosos e dispostos em glomérulos, reunidos em cimas corimbiformes (Figura 1a). Invólucro largamente campanulado, de cor marfim, medindo 4,5-6 $\mathrm{mm}$ de altura por $5-7 \mathrm{~mm}$ de diâmetro (Figura 1b). Brácteas involucrais 9-10-seriadas; as externas, obovadas e rotundas no ápice, de 2-2,5 $\mathrm{mm}$ de comprimento por $2 \mathrm{~mm}$ de largura, com dorso coberto de pêlos lanosos, escassos pêlos glandulares e estereoma de $0,5 \mathrm{~mm}$ de altura; as medianas e internas, espatuladas (4-5,5 mm de comprimento por 1,7-2 $\mathrm{mm}$ de largura), obtusas até rotundas no ápice, com pêlos lanosos e glandulares no dorso e estereoma de 1-2,5 mm de altura (Figura 1e). Flores branco-esverdeadas, dimorfas. As marginais, cerca de 350-400, femininas e filiformes, apresentam corola de 33,2 $\mathrm{mm}$ de comprimento e ápice 3-dentado (Figura 1c); dentes deltóides, brevíssimos, com pêlos glandulares (Figura 1c); estigma de 3,5 


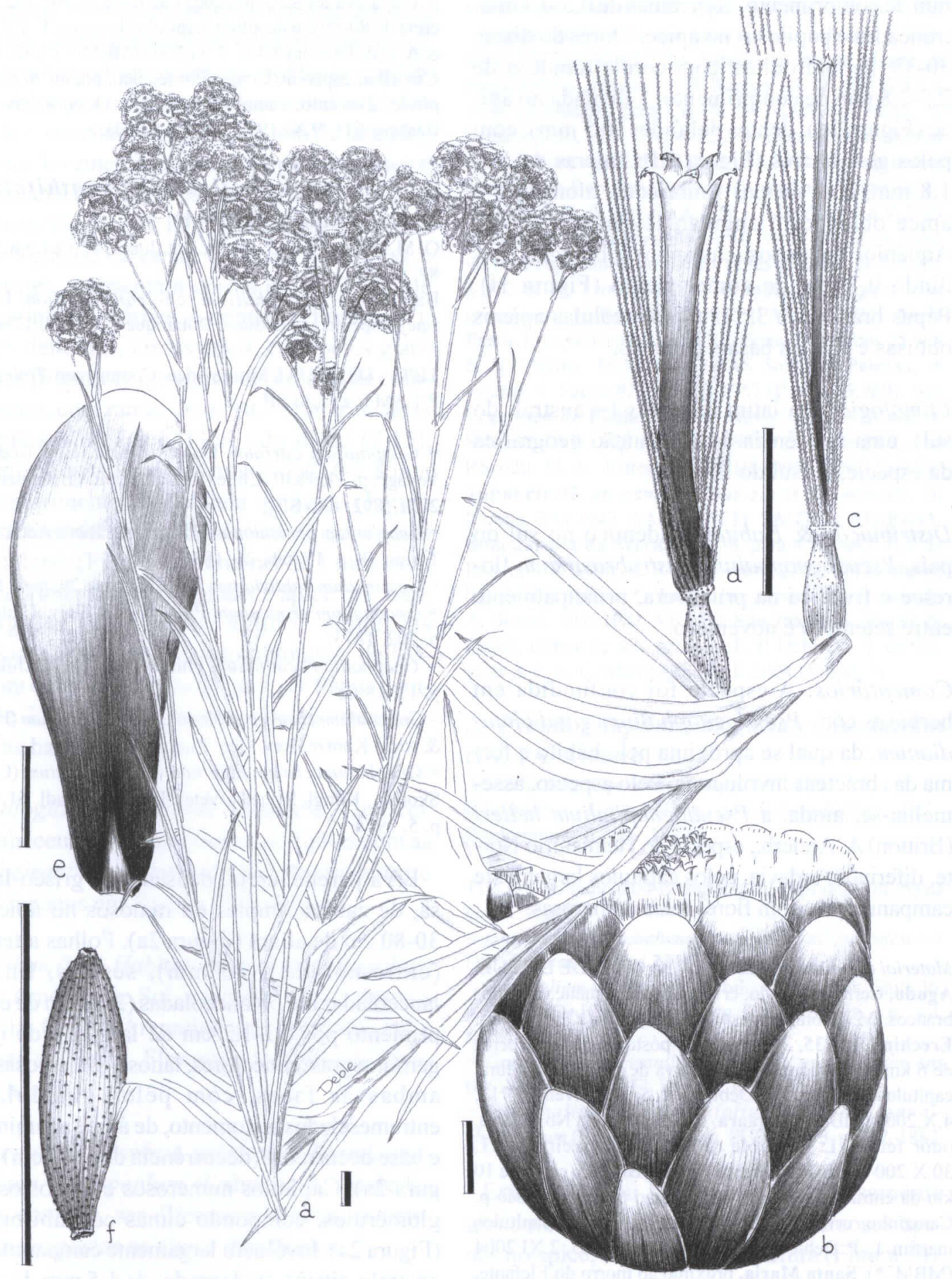

FIGURA 1 - Pseudognaphalium austrobrasilicum Deble \& Marchiori. Ápice do ramo florífero (a). Capítulo (b). Flor marginal (c). Flor do disco (d). Bráctea involucral interna (e). Aquênio (f). Escala a $=1 \mathrm{~cm} ; \mathrm{b}, \mathrm{c}$, $\mathrm{d}, \mathrm{e}, \mathrm{f}=1 \mathrm{~mm}$. 
$\mathrm{mm}$ de comprimento, com ramas de 0,5-0,7 $\mathrm{mm}$, truncadas e papilosas no ápice. Flores do disco, $30-35$, hermafroditas, com corola tubulosa de 2,5-2,8 mm de comprimento, 5-dentada no ápice (Figura 1d); dentes deltóides $(0,5 \mathrm{~mm})$, com pêlos glandulares (Figura 1d); anteras de 1,6$1,8 \mathrm{~mm}$, com caudas fimbriadas, alongadas e ápice oblongo, triangular, levemente agudo. Aquênios papilosos, castanhos, oblongos, medindo $0,7 \mathrm{~mm}$ de comprimento (Figura 1f). Pápus branco, de $3,5 \mathrm{~mm}$, com células apicais obtusas e células basais patentes.

Etimologia: Do latim australis (= austral, do sul), uma referência à distribuição geográfica da espécie, no sul do Brasil.

Distribuição \& Habitat: Endêmico no sul do país, Pseudognaphalium austrobrasilicum floresce e frutifica na primavera, principalmente entre setembro e novembro.

Comentários: A espécie foi confundida em herbário com Pseudognaphalium gaudichaudianum, da qual se aproxima pelo hábito e forma das brácteas involucrais. Pelo aspecto, assemelha-se, ainda, a Pseudognaphalium helleri (Britton) A. Anderb., espécie do Hemisfério Norte, diferindo, todavia, pelos capítulos largamente campanulados, com flores mais numerosas.

Material examinado: BRASIL: RIO GRANDE DO SUL: Agudo, Cerro do Agudo, erva na beira da mata, capítulos brancos, M. Sobral et al. 4.310, IX.1985 (ICN 66.957). Erechim, RS 135, $2 \mathrm{~km}$ antes do posto de pedágio, cerca de $6 \mathrm{~km}$ da entrada da cidade, erva de $100 \mathrm{~cm}$ de altura, capítulos marfim, L. P. Deble \& A. S. de Oliveira 5.712, 4.X.2004 (MBM, *). Itaara, BR 158, p. Vila Nova, erva, odor fétido, L. P. Deble \& A. S. de Oliveira 5.711, 30.X.2004 (MBM, *). Passo Fundo, BR 285, cerca de 10 $\mathrm{km}$ da entrada da cidade, próximo ao trevo de acesso $\mathrm{p}$. Carazinho, erva ereta de $90 \mathrm{~cm}$, odor fétido, capítulos marfim, L. P. Deble \& A. S. de Oliveira 5.463, 2.XI.2004 (MBM, *). Santa Maria, próximo ao morro do Elefante, erva ereta de $80 \mathrm{~cm}$, odor fétido, abundante, L. P. Deble \& A. S. de Oliveira 5.678, 27.X.2004 (MBM, *); Campus da UFSM, L. Z. Ethur, 03.IX.1993 (SMDB 4.986); Camobi, A. C. F. Matos et al., 26.X.1992 (SMDB 4.665). São Sepé, p. Caçapava do Sul, em campo na beira da BR 392, erva ereta de $80-90 \mathrm{~cm}$ de altura, capítulos brancos, L. P. Deble \& A. S. de Oliveira 5.465, 1.XI.2003 (MBM, *). PARANÁ: Curitiba, capão do Centro Politécnico, planta $70 \mathrm{~cm}$, capítulo alvacento, campo limpo, seco, O. S. Ribas \& E. Barbosa 611, 9.XI.1993 (MBM, CESJ).

\section{Pseudognaphalium cheiranthifolium (Lam.) Hilliard \& Burtt}

O. M. Hilliard \& B. L. Burtt, Bot. Journ. of the Linn. Soc., 82, p. 205, 1981.

Basiônimo: Gnaphalium cheiranthifolium Lam., Encyclopédie Méthodique Botanique 2, p. 752, 1786.

TIPO - URUGUAI, Montevideo, Commerson. Holotypus P-LAM n.v., foto SI!

= Gnaphalium citrinum Hook. \& Arn., Bot. Beechey Voyage, p. 31, 1830 [Chile, Hualqui, C. E. O. Kuntze s.n., 20.II.1892, foto SI!];

$=$ Gnaphalium paniculatum Colla, Mem. Reale Accad. Sci. Torino 38, p. 17, tab. 26, 1835;

= Gnaphalium valdivianum Phil., Linnaea 29, p. 6, 1857;

= Gnaphalium araucanum Phil., Anales Univ. Chile 43, p. 502, 1873;

= Gnaphalium acutifolium Phil., Anales Univ. Chile 90, p. 12, 1895;

$=$ Gnaphalium cheiranthifolium Lam. var. citrinum $($ Hook. \& Arn.) Kuntze, Rev. Gen. Pl. 3, p. 151, 1898;

$=$ Gnaphalium cheiranthifolium var. paniculatum (Colla) Skottsb., Kongl. Svenska Vetensk. Acad. Handl. 51, n. 9, p. $5,1914$.

Erva perene, ereta, densamente gríseo-lanosa, de caules simples ou ramosos no ápice, e $30-80 \mathrm{~cm}$ de altura (Figura $2 \mathrm{a}$ ). Folhas alternas (entre-nós de 5-25 mm), sésseis, linearlanceoladas até oblanceoladas $(2-10 \mathrm{~cm}$ de comprimento por $0,2-1,2 \mathrm{~cm}$ de largura), de margens íntegras, concolores, lanoso-tomentosas em ambas as faces, com pêlos glandulares entremesclados ao tomento, de ápice acuminado e base decurrente (decurrência de até $2 \mathrm{~cm}$ ) (Figura 2a). Capítulos numerosos e dispostos em glomérulos, compondo cimas corimbiformes (Figura 2a). Invólucro largamente campanulado, amarelo-citrino ou dourado, de 4-5 mm de altura e diâmetro (Figura 2b). Brácteas involucrais 6-7-seriadas; as externas, ovadas e agudas no ápice, de 2-3 mm de comprimento por 1,5-2 mm 
de largura, com dorso coberto de pêlos lanosos, escassos pêlos glandulares e estereoma de 0,7 $\mathrm{mm}$ de altura (Figura 2e); as medianas e internas, oblongas ou oblongo-lanceoladas (3,5-4 $\mathrm{mm}$ de comprimento por 1- 1,5 $\mathrm{mm}$ de largura), de ápice levemente agudo, com pêlos lanosos e glandulares no dorso e estereoma de 1,5-2,5 mm de altura (Figura 1e). Flores amarelas, dimorfas. As marginais, cerca de 130-260, femininas e filiformes, apresentam corola de 3-3,2 mm de comprimento e ápice 4-dentado (Figura 2c); dentes deltóides, brevíssimos, com pêlos glandulares (Figura 1c); estigma de 3,5 mm de comprimento, com ramas de $0,5-0,7 \mathrm{~mm}$, truncadas e papilosas no ápice. Flores do disco (7-15), hermafroditas, de corola tubulosa $(2,6-2,8 \mathrm{~mm}$ de comprimento), 5-dentada no ápice (Figura 1d); dentes deltóides (0,3-0,5 mm), com pêlos glandulares (Figura 1d); anteras de $1 \mathrm{~mm}$, com caudas fimbriadas, alongadas e ápice oblongo, triangular, levemente agudo. Aquênios papilosos, castanhos, ovado-oblongos, de 0,5$0,6 \mathrm{~mm}$ de comprimento (Figura 1f). Pápus branco, de 3,5 mm, com células apicais obtusas e células basais patentes.

Etimologia: Ao conceber a espécie, Lamarck reconheceu a semelhança de suas folhas com as de Cheiranthus (Brassicaceae), gênero descrito por Linnaeus em Species Plantarum.

Distribuição \& Habitat: Amplamente distribuída na América do Sul, a espécie ocorre desde a Bolívia, Chile e Argentina até o Uruguai, sul e sudeste do Brasil. Floresce nos meses de fevereiro a junho.

Comentários: Espécie próxima a Pseudognaphalium leucopeplum (Cabrera) A. Anderb., pode, contudo, ser diferenciada pelas características expostas na chave dicotômica.

Material examinado: BRASIL: MINAS GERAIS: Passa Quatro, Serra da Mantiqueira, J. Vidal, XI.1948 (MBM). RIO GRANDE DO SUL: Bom Jesus, próximo ao arroio Itaimbezinho, N. Silveira 8.193, 21.IV.1990 (HAS 61.581).
Cambará do Sul, na rodovia para São Francisco de Paula, capoeira, inflorescência amarela, N. Silveira 9.738, 28.III.1987 (HAS 61.575). Esteio, para Porto Alegre, in campestribus graminosis, B. Rambo, 02.XI.1931 (PACA 474). Gramado, para Canela, in incultis ad viam, A. Bruxel, 27.III.1937 (PACA 2.328); idem, in dumetosis ad viam, B. Rambo, 27.III.1937 (PACA 29.829). Jaquirana, estrada para Bom Jesus, erva ereta, capítulos amarelos, L. P. Deble, A. S. de Oliveira \& J. N. C. Marchiori, 14.V.2004 (MBM, *). Lagoa Vermelha, a $10 \mathrm{~km}$ da cidade, na rodovia para Tupiriambá, no campo, flores amarelas, N. Silveira 2.972 \& R. Frosi (HAS). Nonoai, in campestribus graminosis, B. Rambo, III.1945 (PACA 28.220). Nova Prata, Estação Experimental Rio Branco, J. Mattos 25.968 \& N. Mattos, 16.III.1984 (HAS 56.022). Pelotas, in incultis, J. Sacco 825, 11.XII.1957 (PACA 63.969). São Francisco de Paula, Potreiro Novo, herba ad viam, A. Sehnem, 23.II.1978 (PACA 86.953); cerca de $18 \mathrm{~km}$ da RS 020, M. R. Ritter 825, 31.III.1995 (ICN 113.940). Tupanciretã, in campestribus siccis graminosis, B. Rambo, 29.I.1942 (PACA 9.751). SANTA CATARINA: Bom Jardim da Serra, SC 438, para a Serra do Rio do Rastro, L. P. Deble, A. S. de Oliveira \& J. N. C. Marchiori, 06.III.2004 (MBM, *). Lages, in campestribus dumetosis, A. Bruxel, 1935 (PACA 6.822). São Joaquim, distrito de Pericó, campo de solo rochoso, L. P. Deble, A. S. de Oliveira \& J. N. C. Marchiori, 06.III.2004 (MBM, *).

\section{Pseudognaphalium gaudichaudianum} (DC.) A. Anderb.

A. Anderberg, Opera Bot. 104, p. 147, 1991.

Basiônimo: Gnaphalium gaudichaudianum DC., Prodromus 6, p. 226, 1837.

TIPO - C. Gaudichaud-Beaupré, s.n., in Brazil. Holotypus G n.v., foto SI!

$=$ Gnaphalium gaudichaudianum DC. var. subrufescens DC., Prodromus 6, p. 226, 1837;

= Gnaphalium mendoncinum Phil., Anales Univ. Chile 36, p. 184, 1870 [Chile, Mendonza, R. A. Philippi, s.n., s.d. foto!];

= Gnaphalium cheiranthifolium Lam. var subrufescens (DC.) Baker, Mart. Fl. Bras. 6, 3, p. 122, 1882;

= Gnaphalium cheiranthifolium Lam. var gaudichaudianum (DC.) Baker, Mart. Fl. Bras. 6, 3, p. 122, 1882.

Erva anual ou bianual, ereta, densamente glandulosa, de caules simples ou ramosos apenas no ápice, e 40-100 cm de altura (Figura 3a). Folhas alternas (entre-nós de 3-10 mm), sésseis, lineares até linear-lanceoladas $(2-10 \mathrm{~cm}$ de comprimento por $0,1-0,7 \mathrm{~cm}$ de largura), de margens íntegras ou algo revolutas, discolores, 


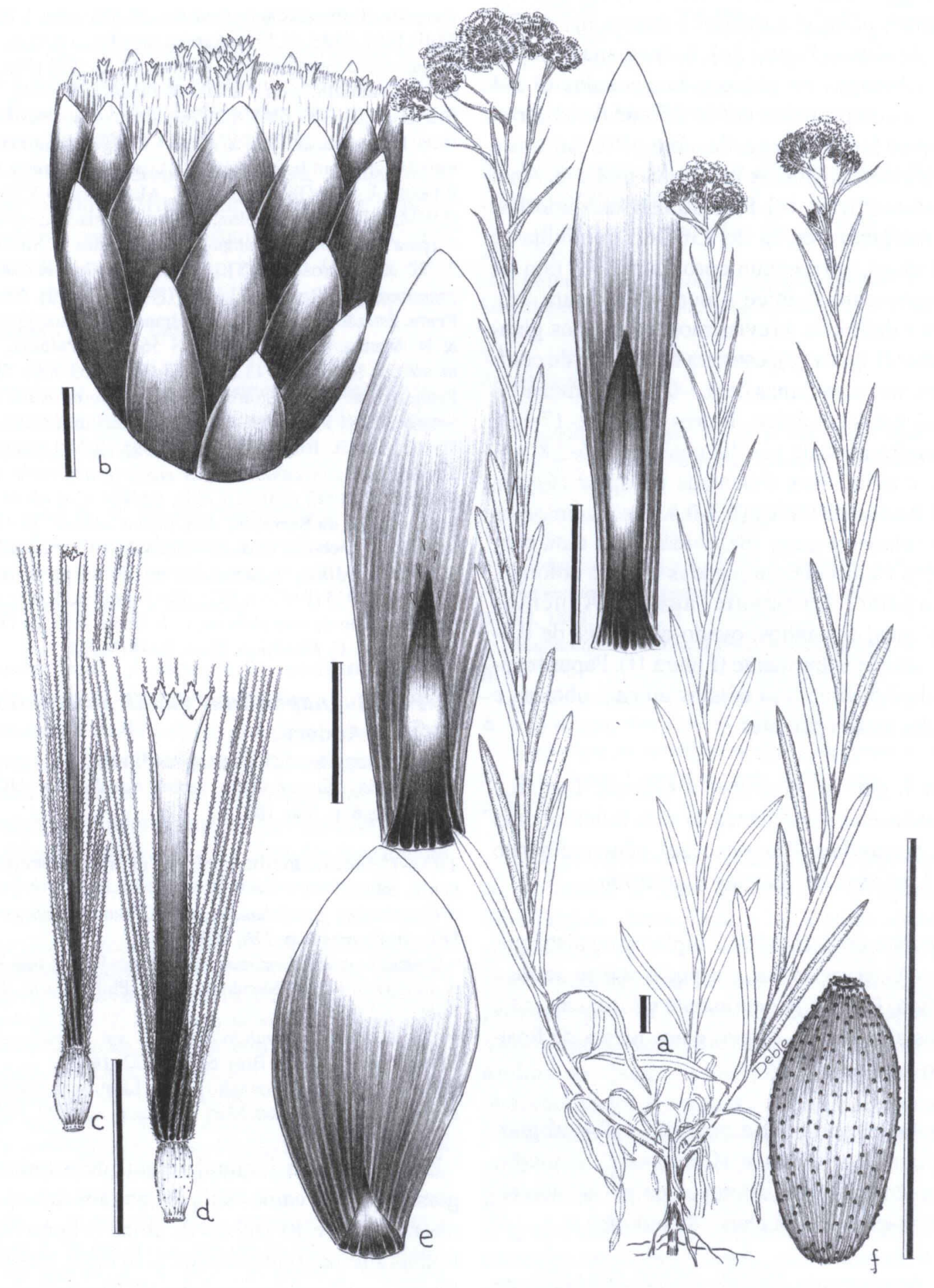

FIGURA 2 - Pseudognaphalium cheiranthifolium (Lam.) Hilliard \& Burtt. Planta (a). Capítulo (b). Flor marginal (c). Flor do disco (d). Brácteas involucrais (e). Aquênio (f). Escala a =1cm; b, c, d, e, f=1mm. 
incano-tomentosas na face abaxial e densamente glandulosas na adaxial, com ápice acuminado e base decurrente (decurrência de até $1,5 \mathrm{~cm}$ ) (Figura 3a). Capítulos numerosos, em glomérulos compondo cimas corimbiformes (Figura 3a). Invólucro largamente campanulado, estramíneo, medindo 3-4 $\mathrm{mm}$ de altura por 3-5 $\mathrm{mm}$ de diâmetro (Figura 3b). Brácteas involucrais 8-9-seriadas; as externas, ovadas, obtusas até rotundas no ápice, de 2-2,5 mm de comprimento por 1,5 $\mathrm{mm}$ de largura, com dorso coberto de pêlos lanosos, escassos pêlos glandulares e estereoma de $0,5 \mathrm{~mm}$ de altura (Figura 3e); as medianas e internas, oblongo-espatuladas (3-4 mm de comprimento por $1 \mathrm{~mm}$ de largura), obtusas a rotundas no ápice, com pêlos lanosos e glandulares no dorso, e estereoma de 1,5-2,5 $\mathrm{mm}$ de altura (Figura 3e). Flores branco-amareladas ou branco-esverdeadas, dimorfas. As marginais, cerca de 160-270, femininas e filiformes, com corola de 2,5-2,8 mm de comprimento e ápice 3-dentado (Figura 3c); dentes deltóides, brevíssimos, com pêlos glandulares (Figura 3c); estigma de $3 \mathrm{~mm}$ de comprimento, com ramas de $0,5 \mathrm{~mm}$, truncadas e papilosas no ápice. Flores do disco, 7-15, hermafroditas, com corola tubulosa (2,2-2,4 mm de comprimento), 5-dentada no ápice (Figura 3d); dentes deltóides ( 0,4 $\mathrm{mm}$ ), com pêlos glandulares (Figura 3d); anteras de $1,5 \mathrm{~mm}$, com caudas fimbriadas, alongadas e ápice oblongo, triangular, levemente agudo. Aquênios papilosos, castanho-escuros, ovadooblongos, de 0,4-0,5 $\mathrm{mm}$ de comprimento (Figura 3f). Pápus branco, de 2,5 mm, com células apicais obtusas e células basais patentes.

Etimologia: Espécie dedicada a seu coletor, o botânico e farmacêutico francês Charles Gaudichaud-Beaupré (1789-1854).

Distribuição \& Habitat: A distribuição geográfica estende-se do sul da Bolívia, Chile e Argentina, até o Uruguai e sul do Brasil, ocorrendo de dunas costeiras até 1.700 m.s.m. (Freire, 1995). Material florido pode ser encontrado em quase todos os meses do ano; floresce com maior intensidade entre janeiro e maio.

Comentários: Pseudognaphalium gaudichaudianum separa-se das demais espécies brasileiras por suas folhas lineares, discolores, com pêlos curtos e glandulares na face adaxial e pubescência incana na abaxial.

Material examinado: BRASIL: RIO GRANDE DO SUL: Aceguá, Serra de Aceguá, na divisa com o Uruguai, erva de $40 \mathrm{~cm}$, capítulos esbranquiçados, L. P. Deble \& A. S. de Oliveira, 22.IX.2003 (MBM, *). Alegrete, Cerro do Tigre, erva de $60 \mathrm{~cm}$, folhas discolores, capítulos estramíneos, flores branco-esverdeadas, L. P. Deble \& A. S. de Oliveira, 29.IX.2005 (CNPO, MBM, *). Arroio dos Ratos, fazenda Faxinal, K. Hagelund 13.255, 5.I.1980 (ICN 68.481). Bagé, BR 153, Km 84, erva na beira da estrada, capítulos brancos, M. Sobral \& C. Grabauska, VI.1985 (ICN 65.313); Casa de Pedra, na beira da estrada, M. R. Ritter 639, 13.VI.1991 (ICN 92.446); BR 153, cerca de $15 \mathrm{~km}$ de Aceguá, abundante na beira da estrada, capítulos estramíneos, flores branco-esverdeadas, L. P. Deble \& A. S. de Oliveira, 9.III.2003 (MBM, *). Caçapava do Sul, Cerro do Ricardinho, M. Sobral 6.397, I.1990 (ICN 90.722); idem, M. Sobral 3.902, V.1985 (ICN 88.823); Guaritas, em barranco arenoso, erva de $80 \mathrm{~cm}$, ramosa no ápice, capítulos estramíneos, L. P. Deble \& A. S. de Oliveira, 9.I.2004 (MBM, *). Cambará do Sul, Faxinal, erva na beira do arroio Faxinalzinho, M. Sobral 2.848, I.1984 (ICN 65.232). Dom Pedrito, BR 293, cerca de $10 \mathrm{~km}$ do trevo de acesso a cidade, L. P. Deble \& A. S. de Oliveira, 13.III.2004 (MBM, *). Guaíba, BR 116, Km 32, beira da estrada, N. I. Matzenbacher, 18.XII.1983 (ICN 59.372). Passo Fundo, A. R. Schultz, 13.I.1949 (ICN 685). Pelotas, Instituto Agronômico do Sul, I. Ary 18, 23.I.1950 (ICN 31.519); Laranjal, I. Edésio 11.018, 25.I.1950 (ICN 17.973); Taim, I. Edésio 11.053, 30.I.1950 (ICN 31.966). Santa Maria, chácara da prefeitura, G. Rau, 26.II.1940 (SMDB 390); Campus da UFSM, L. Z. Ethur, 20.V.1993 (SMDB 5.074); idem, L. Z. Ethur, 01.II.1994 (SMDB 5.137).

\section{Pseudognaphalium leucopeplum (Cabrera) A. Anderb.}

A. Anderberg, Opera Bot. 104, p. 147, 1991.

Basiônimo: Gnaphalium leucopeplum Cabrera, Bol. Soc. Argent. Bot. 9, p. 383, 1961.

TIPO - ARGENTINA, Prov. Buenos Aires, Juancho, en dunas semifijas, A. L. Cabrera 2.686, 11.I.1933. Holotypus LP! 


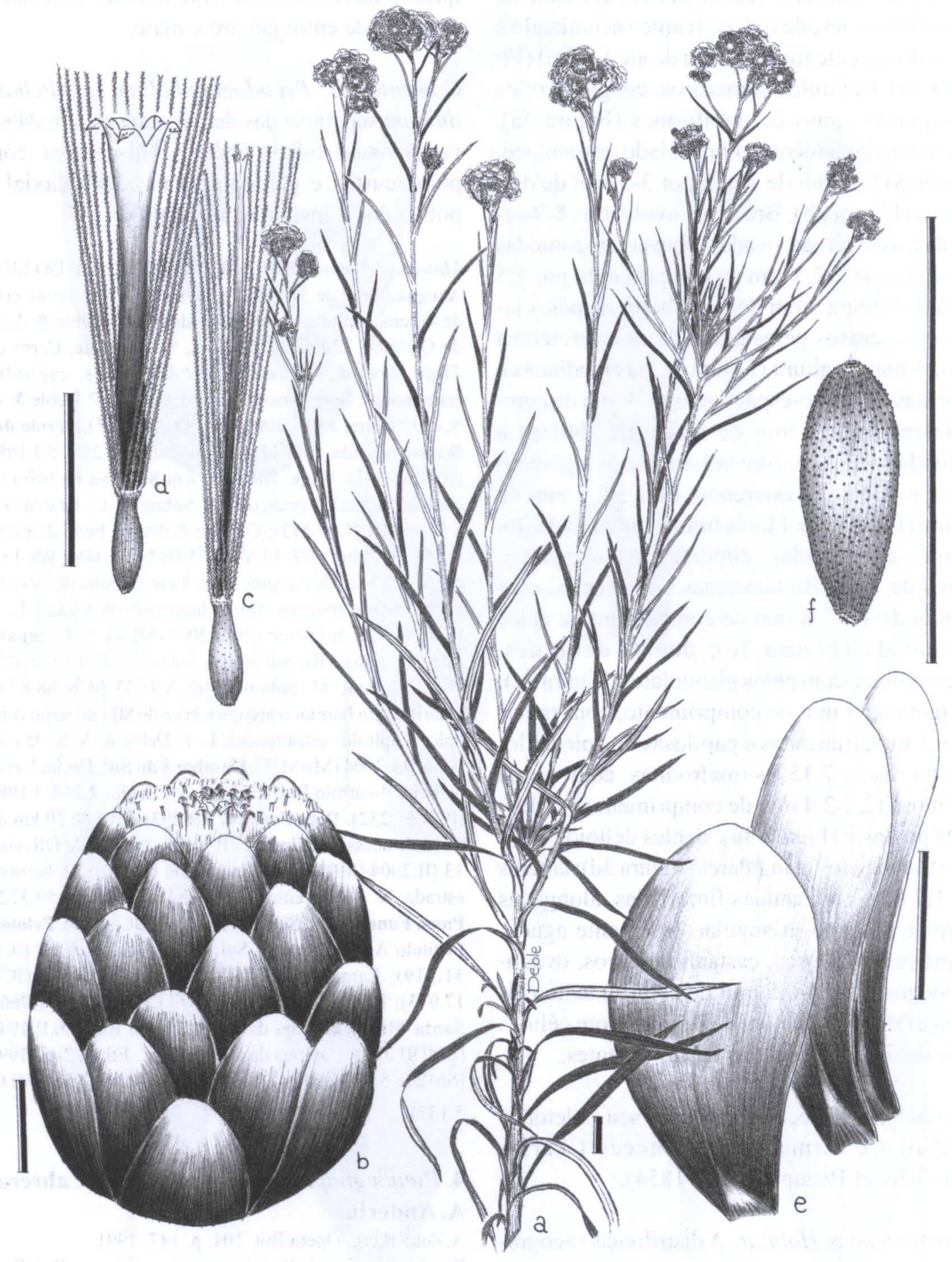

FIGURA 3 - Pseudognaphalium gaudichaudianum (DC.) A. Anderb. Ápice do ramo florífero (a). Capítulo (b). Flor marginal (c). Flor do disco (d). Brácteas involucrais (e). Aquênio (f). Escala a =1cm; b, c, d, e, f= $1 \mathrm{~mm}$. 
Erva perene, densamente incano-lanosa, ereta, de 40-100 cm de altura e caules simples ou ramosos no ápice (Figura 4a). Folhas alternas (entre-nós de 4-20 mm), sésseis, linearlanceoladas (3-13 cm de comprimento por 0,2$1 \mathrm{~cm}$ de largura), de margens íntegras, concolores, lanoso-tomentosas em ambas as faces, desprovidas de pêlos glandulares, com ápice acuminado e base decurrente (decurrência de até $1,5 \mathrm{~cm}$ ) (Figura 4a). Capítulos numerosos e dispostos em glomérulos, reunidos em cimas corimbiformes (Figura 4a). Invólucro largamente campanulado, estramíneo ou pardo-amarelado, de 5-6,5 $\mathrm{mm}$ de altura por 5-7 $\mathrm{mm}$ de diâmetro (Figura 4b). Brácteas involucrais 6-7-seriadas; as externas, ovadas e agudas no ápice, de 2-3,5 $\mathrm{mm}$ de comprimento por 1,5-2 $\mathrm{mm}$ de largura, com dorso coberto de pêlos lanosos, escassos pêlos glandulares e estereoma de $1 \mathrm{~mm}$ de altura (Figura 4e); as medianas e internas, oblongas ou oblongo-lanceoladas (4,5-6 $\mathrm{mm}$ de comprimento por $1,5 \mathrm{~mm}$ de largura), levemente agudas até obtusas no ápice, com pêlos lanosos e glandulares no dorso e estereoma de 1,5-3 $\mathrm{mm}$ de altura (Figura 4e). Flores amarelas, dimorfas. As marginais, cerca de 200-250, femininas e filiformes, com corola de $3 \mathrm{~mm}$ de comprimento e ápice 4-dentado (Figura 4c); dentes deltóides, brevíssimos, com pêlos glandulares (Figura 4c); estigma de 3,5 mm de comprimento, com ramas de $0,7 \mathrm{~mm}$, truncadas e papilosas no ápice. Flores do disco, 10-15, hermafroditas, de corola tubulosa $(2,8 \mathrm{~mm}$ de comprimento), 5-dentada no ápice (Figura 4d); dentes deltóides $(0,5 \mathrm{~mm})$, com pêlos glandulares (Figura 4d); anteras de $1 \mathrm{~mm}$, com caudas fimbriadas, alongadas e ápice oblongo, triangular, levemente agudo. Aquênios papilosos, castanhos, oblongos, de 0,7-0,8 mm de comprimento (Figura 4f). Pápus branco-amarelado, de 3$3,5 \mathrm{~mm}$, com células apicais obtusas e células basais patentes.

Etimologia: Do latim leucos (= branco) e peplum (= manto honorífico de Minerva, manto de cerimônia para uso dos deuses), uma refe- rência ao tomento incano-lanoso que cobre a espécie.

Distribuição \& Habitat: Pseudognaphalium leucopeplum ocorre no litoral do Uruguai e no centro-sul da Argentina (províncias de Buenos Aires, Chubut, Córdoba, La Rioja, Neuquén, Rio Negro, San Juan, San Luis e Tucumán). No Brasil, sua ocorrência é bastante rara, sendo conhecido um único registro, no centro do Estado do Rio Grande do Sul. Pseudognaphalium leucopeplum floresce e frutifica no verão.

Comentários: Muito próxima de Pseudognaphalium cheiranthifolium, separa-se pela ausência, nas folhas, de pêlos glandulares entremesclados a lanosos, pelos capítulos algo maiores, de cor estramínea ou pardo-amarelada, bem como pelos aquênios oblongos, de maior tamanho.

Observação: Ao descrever Gnaphalium leucopeplum, Cabrera (1961) citou um parátipo do Rio Grande do Sul. A análise deste material (PACA 28.220) demonstra, todavia, que o mesmo corresponde a um exemplar de Pseudognaphalim cheiranthifolium, pois apresenta capítulos dourados e longos pêlos glandulares entremesclados a pêlos lanosos, nas folhas.

Material examinado: BRASIL: RIO GRANDE DO SUL: Itaara, Val de Serra, K. Hagelund 12.273, 22.II.1978 (ICN). Material adicional examinado: ARGENTINA: BUENOS AIRES: Cabo San Antonio, Fabris \& Cullen 2.556 (LP); Valeria del Mar, dunas costaneras, J. Frangi, I.1971 (CTES, MBM). LA PAMPA: Anzoategui, M. Biraben 3.006, II.1941 (LP). URUGUAI: MONTEVIDEO: Malvin, W. G. Herter, s.d., 81.701 (MVM, LP).

\section{AGRADECIMENTOS}

Os autores agradecem aos curadores e funcionários dos herbários consultados, bem como a Mara Rejane Ritter, pelo acesso à coleção de Karner Hagelund, e a Norma Deginani (SI), Susana Freire e Laura Iharlegui (LP), pela consulta a materiais tipo e fotótipos. 


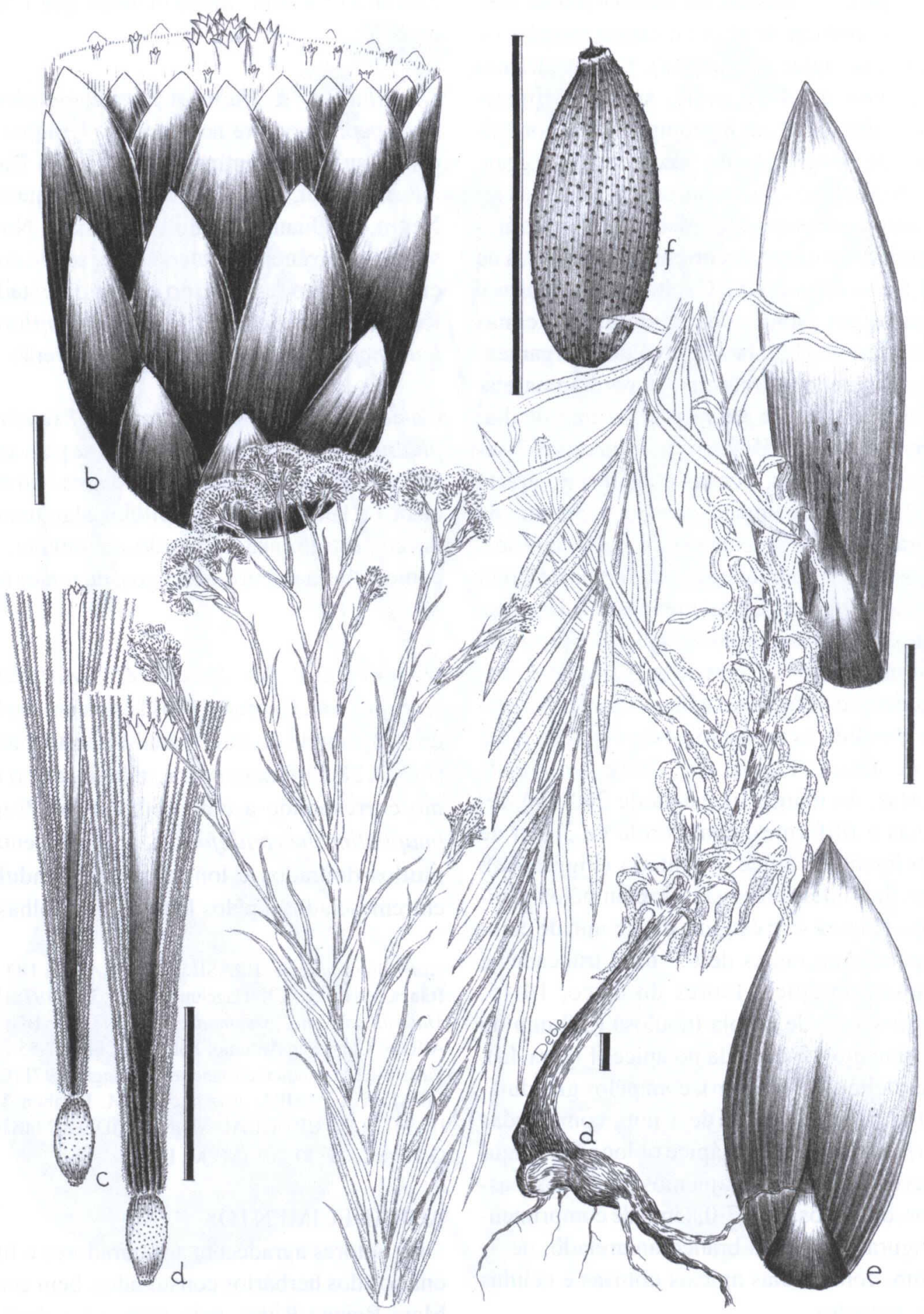

FIGURA 4 - Pseudognaphalium leucopeplum (Cabrera) A. Anderb. Planta (a). Capítulo (b). Flor marginal (c). Flor do disco (d). Brácteas involucrais (e). Aquênio (f). Escala a $=1 \mathrm{~cm} ; \mathrm{b}, \mathrm{c}, \mathrm{d}, \mathrm{e}, \mathrm{f}=1 \mathrm{~mm}$. 


\section{BIBLIOGRAFIA}

Anderberg, A. Taxonomy and phylogeny of the tribe Gnaphalieae (Asteraceae). Opera Bot., Copenhagen, n. 104, p. 1-195, 1991.

Baker, J. F. Compositae. In: Martius, C. F. Flora Brasiliensis. München, Wien and Leipzig, 1882, v. 6, n. 3, p.1-132.

Ballard, H. E., Feller, D. S., Nesom, G. L. Cliff cudweed at specific rank in Pseudognaphalium (Asteraceae: Gnaphalieae). Sida, v. 21, n. 2, p. 777-779, 2004.

Cabrera, A. L. Observaciones sobre las InuleaeGnaphalineae (Compositae) de América del Sur. Bol. Soc. Argent. Bot., La Plata, v. 9, p. 362-383, 1961.

Cabrera, A. L. Compositae. In: Cabrera, A. L. Flora de la Provincia de Buenos Aires (Argentina). Buenos Aires: INTA, 1963. Tomo IV, parte VI, p. 161-166.

Cabrera, A. L. Compositae. In: Correa, M. N. Flora Patagonica (Argentina). Buenos Aires: INTA, 1971. Tomo VIII, parte VII, p. 109-115.

Cabrera, A. L. Compositae. In: Burkart, A. Flora Ilustrada de Entre Ríos (Argentina). Buenos Aires: INTA, 1974. Tomo VI, parte VI, p. 315-317.

Cabrera, A. L. Compositae. In: Cabrera, A. L. Flora de la Provincia de Jujuy (Argentina). Buenos Aires: INTA, 1978. Tomo VIII, parte X, p. 275-288.

De Candolle, A. P. Prodr. Syst. Nat. Reg. Veget. Paris, 1837. v. 6, p. 218-268.

Dillon M. O., Sagástegui, A. Sinopsis de los géneros de Gnaphaliinae (Asteraceae-Inuleae) de Sudamérica. Arnaldoa, Trujillo, v. 1, n. 2, p. 5-91, 1991.

Dillon, M. O., Sagástegui, A. Flora of Peru (J. Francis Macbride and collaborators). Family Asteraceae: Part V. Fieldiana, Chicago, n. 26, p. 32-41, 1991.

Freire, S. E. Asteraceae. Tribu IV. Inuleae. Flora Fanerogámica Argentina, Córdoba, n. 14, p. 1-60, 1995.
Groves, B. E. Contributions to a chromosome atlas of the New Zeland flora. 19. Gnaphalium (Compositae). New Zeland J. Bot., n. 15, p. 17-18, 1977.

Hilliard, O. M., Burtt, B. L. Some generic concepts in Compositae-Gnaphaliinae. Bot. J. Linn. Soc., n. 82, p. 181-232, 1981.

Kirpichnikov, M. E. Gnaphalium L. In: Komarov, V. L. (ed.), FI. URSS. Moscou, Leningrado, p. 381-404, 1959.

Kirpichnikov, M. E., Kuprijanova, L. A. Morphological, geographical and palynological contributions to the understanding of the genera of the subtribe Gnaphaliinae. Acta Inst. Bot. V. F. Komarov Acad Sci URSS, v. 1, n. 9, p. 7-37, 1950.

Lamarck, J. B. Encyclopedie Méthodique Botanique. Paris, 1786-1788. v. 2.

Leins, P. Pollensystematische studien an Inuleen. 1. Tarchonanthinae, Plucheinae, Inulinae, Buphthalminae. Bot. Jahrb. Syst., Leipzig, v. 91, n. 2, p. 91146, 1971.

Leins, P. Pollensystematische studien an Inuleen. 2. Filagininae. Bot. Jahrb. Syst., Leipzig, v. 93, n. 4, p. 603-611, 1973.

Lombardo, A. Flora Montevidensis. Montevideo: Concejo Departamental, 1983. Tomo II, p. 228-229.

Nesom, G. L. Pseudognaphalium austrotexanum (Asteraceae: Gnaphalieae), a new species from southeastern Texas and adjacent Mexico. Sida, v. 21, n. 2, p. 781-789, 2004.

Nesom, G. L. Pseudognaphalium canescens (Asteraceae: Gnaphalieae) and putative relatives in western North America. Sida, v. 19, n. 3, p. 507-511, 2001.

Turner, B. L. Chromosome number in Compositae. 12. Australian species. Amer. J. Bot., n. 57, p. 382-389, 1970. 